\title{
Acetaminophen or Ibuprofen: A Riddle Worth Solving in an Acute Attack of Pediatric Migraine
}

\author{
Sonali Singh ${ }^{1} \cdot$ Biswaroop Chakrabarty ${ }^{1}$ (i) \\ Received: 21 August 2020 / Accepted: 21 August 2020 / Published online: 28 August 2020 \\ (C) Dr. K C Chaudhuri Foundation 2020
}

Pediatric migraine is a common entity with an overall prevalence of approximately $8 \%$. In school aged children, in the first decade of life, the prevalence is $5-10 \%$, which increases to $15 \%$ in adolescence. Migraine leads to disability in the form of school absenteeism, poor scholastic performance and impairment in co-curricular activities [1]. It is the commonest cause of pediatric headache reported at both hospital and community level in India. It is imperative to have effective and affordable therapeutic strategies for migraine treatment in place and therein lies the importance of the study by Pavithra et al. [2].

The recent recommendation by the American Academy of Neurology and American Headache Society on acute treatment of migraine in children and adolescents states that nonprescription analgesics like oral ibuprofen and acetaminophen are beneficial in childhood and adolescent migraine. Almotriptan, sumatriptan, zolmitriptan and naproxen are recommended and approved by FDA in patients aged $12 \mathrm{y}$ and above. Only rizatriptan is FDA approved in the first decade of life in patients aged $6 \mathrm{y}$ and above. The guidelines separately mention level B recommendation for ibuprofen as an analgesic agent in pediatricmigraine [3].

Acetaminophen is a commonly used antipyretic and analgesic agent across all age groups. Ibuprofen exerts its analgesic effect by inhibiting cyclooxygenase 2 and 3 , whereas acetaminophen mediates analgesia through its effects on N-methyl-Dasparatate, substance $\mathrm{P}$, serotonin, cannabinoid and nitrix oxide synthase [4]. Both the drugs are relatively safe. Acetaminophen can be given at all ages, although overdose may lead to hepatotoxicity. Ibuprofen may occasionally cause gastric irritation and rarely renal toxicity, thus warranting caution in its usage [5].

Biswaroop Chakrabarty

biswaroopchakrabarty@gmail.com

1 Child Neurology Division, Department of Pediatrics, AIIMS, New Delhi, India
Till date only two studies including the current one by Pavithra et al. have compared the efficacy of ibuprofen with acetaminophen in pediatric onset migraine. In the study by Hamalainen et al., they compared single dose ibuprofen, acetaminophen and placebo in a three armed randomized crossover trial. The current study by Pavithra et al. is a two armed randomized control trial with one arm receiving acetaminophen and the other arm, ibuprofen. Both the studies looked at analgesic action at $2 \mathrm{~h}$ as the primary efficacy endpoint. The current study didn't find any statistically significant difference between the two groups whereas in the other study, ibuprofen performed significantly better than acetaminophen. None of the studies reported any serious adverse effect. Hamalainen et al. included both cases with and without aura beyond a certain degree of severity of pain and evaluation was done on a five point pain severity scale. On the other hand, in the current study by Pavithra et al., all patients with pain were included, those with aura were excluded and evaluation was done on a ten point severity scale. This heterogeneity in study population and effect evaluation can possibly explain the difference in the study outcome [3,6]. The study by Pavithra et al., although done in a limited sample size, makes a strong point for an appropriately designed study evaluating analgesic effect of acetaminophen and ibuprofen in acute attack of pediatric migraine.

\section{Compliance with Ethical Standards}

Conflict of Interest None.

\section{References}

1. Greene K, Irwin SL, Gelfand AA. Pediatric migraine an update. Neurol Clin. 2019;37:815-33.

2. Pavithra V, Mishra D, Behera S, Juneja M. Paracetamol versus ibuprofen for the acute treatment of migraine headache in children: a blinded randomized controlled trial. Indian J Pediatr. 2020. https:// doi.org/10.1007/s12098-020-03315-x. 
3. Oskoui M, Pringsheim T, Holler-Managan Y, et al. Practice guideline update summary: acute treatment of migraine in children and adolescents. Report of the guideline development, dissemination, and implementation Subcommittee of the American Academy of neurology and the American headache society. Headache. 2019;59: $1158-73$.

4. Motov S, Butt M, Masoudi A, et al. Comparison of oral ibuprofen and acetaminophen with either analgesic alone for pediatric emergency department patients with acute pain. J Emerg Med. 2020;58: 725-32.
5. Gaglani A, Gross T. Pediatric pain management. Emerg Med Clin N Am. 2018;36:323-4.

6. Hamalainen ML, Hoppu K, Valkeila E, Santavuori P. Ibuprofen or acetaminophen for the acute treatment of migraine in children: a double-blind, randomized, placebo-controlled, crossover study. Neurology. 1997;48:103-7.

Publisher's Note Springer Nature remains neutral with regard to jurisdictional claims in published maps and institutional affiliations. 